\title{
Philosophiques
}

\section{Le Québec ne doit pas se donner une constitution : il en a déjà une qu'il abandonnerait à ses risques et périls}

\section{Gary Caldwell}

Volume 19, numéro 2, automne 1992

Une nation peut-elle se donner la constitution de son choix?

URI : https://id.erudit.org/iderudit/027199ar

DOI : https://doi.org/10.7202/027199ar

Aller au sommaire du numéro

Éditeur(s)

Société de philosophie du Québec

ISSN

0316-2923 (imprimé)

1492-1391 (numérique)

Découvrir la revue

Citer ce document

Caldwell, G. (1992). Le Québec ne doit pas se donner une constitution : il en a déjà une qu'il abandonnerait à ses risques et périls. Philosophiques, 19(2),

191-198. https://doi.org/10.7202/027199ar d'utilisation que vous pouvez consulter en ligne. 


\title{
LE QUÉBEC NE DOIT PAS SE DONNER
}

\author{
UNE CONSTITUTION:
}

IL EN A DÉJÀ UNE QU'IL

ABANDONNERAIT

À SES RISQUES ET PÉRILS

\author{
par \\ Gary Caldwell
}

\begin{abstract}
Dans ce texte, nous débutons avec le constat que le Québec est une société libre et démocratique, où prévalent une qualité de vie et un degré de justice sociale tout à fait exceptionnels. Cet état de choses n'étant pas le fruit du hasard, nous cherchons à mettre le doigt sur les caractéristiques de la société civile et de la culture politique québécoises qui auraient pu, ensemble, produire le résultat que nous nommons la constitution québécoise. Nous tenterons de dégager les grandes lignes - les ressorts principaux - de cette constitution pour ensuite poser la question suivante: peut-on surimposer à celle-ci une autre constitution à partir des visées idéologiques qui ont cours présentement dans l'intelligentsia québécoise?

Comme illustration des conséquences possibles d'une telle intervention globalisante et rationalisante, nous offrons l'exemple de la révolution opérée au sein de la culture politique canadienne par la rupture de ig82 (Acte du Canada avec la Charte). Et finalement, à partir de la prise de position qui est celle de vouloir conserver la constitution actuelle du Québec, nous
\end{abstract}


essayons de faire face à l'enjeu majeur: que faire, face aux velléités républicaines d'une partie importante de la classe politique québécoise et canadienne?

\section{UNE SOCIÉTÉ LIBRE, JUSTE ET DÉMOCRATIQUE}

Au Canada anglais, et dans certains milieux aux Etats-Unis, il s'est formé une conception selon laquelle le Québec est une société intolérante et collectivisante; et pour ces raisons elle est accableee d'une culture politique qui n'est pas libérale. Dans le livre récent de Bercusson et Cooper, Déconféderation: le Canada sans le Québec, cette affirmation est l'un des postulats de leur argumentation.

C'est cette conception de la vie politique québécoise qui permet à des intellectuels américains et canadiens-anglais, comme ceux de ce Colloque, d'avoir la prétention de vouloir expliquer aux Québécois comment devenir une société démocratique et libérale, et en corollaire, la constitution qu'il faudrait pour y arriver. C'est particulièrement ironique d'entendre de tels propos d'intellectuels venant de sociétés où l'on a récemment connu des émeutes raciales comme celles qui se sont produites à Los Angeles et à Toronto au mois d'aviil I992.

Affirmation gratuite de ma part, diraient les apôtres de l'évangile néo-libéral qui voit dans le Québec une société raciste peu respectueuse des libertés individuelles. Prenons donc un peu de distance face à la rhétorique entourant le débat sur la nature de la démocratie québécoise et regardons la performance du Québec relativement à ce qu'on considère comme le but d'une société dèmocratique et libérale, soit la qualité de vie de ses membres ... le degré de bien-être matériel et psychologique dont jouissent les peuples prospères et libres.

Une indication de la liberté qui règne dans une société est l'existence d'élections libres auxquelles participe la population. Au Québec les élections sont libres, encadrées comme elles le sont par une loi électorale qui limite les abus d'argent des autorités en place. De plus, les trois quarts de la population éligible à voter (la quasi-totalité des plus de dix-sept ans) votent régulièrement aux élections fédérales et provinciales. Ce taux de participation se compare très avantageusement avec celui des ÉtatsUnis oủ à peu près la moitié des électeurs potentiels votent aux élections fédérales. Même, il n'est pas rare au Québec que le taux monte à quatre-vingts p. cent lors d'élections pour le parlement québécois, ce qui est très exceptionnel dans les autres provinces. 
Quant au caractère pluraliste du Québec et son ouverture vers l'extérieur, un indicateur révélateur est le nombre d'immigrants reçus par année par mille de population. Depuis que le Québec exerce un certain contrôle sur l'immigration, ce taux, pour cette province, voisine quatre immigrants par mille de population, un taux égal à celui du reste du Canada et qui est le double de celui de la France et quatre fois celui du Royaume-Uni.

Quant au degré de justice sociale et à la plus grande égalité des chances qui en découle, des indicateurs grossiers mais universellement applicables sont le taux de mortalité infantile et l'espérance de vie à la naissance. On ne saurait atteindre des performances si élevées, en termes de ces deux indicateurs, s'il y avait une partie considérable de la population qui n'ait pas accès à l'infrastructure sociale et économique d'une société moderne.

Or, le taux de mortalité infantile du Québec 16,4 par ıoo naissances) est parmi les plus bas au monde, comparable à ceux du Japon et de la Suisse, tout en étant plus bas que ceux des Etats-Unis et de la France. Pour ce qui est de l'espérance de vie à la naissance, le taux du Québec, presque 77 ans, dépasse celui des Etats-Unis, est comparable à celui du Canada dans son ensemble et à celui de la France.

Bas niveau de mortalité infantile, espérance de vie très élevée, ce sont là des indicateurs positifs de la qualité de vie. Homicides et suicides sont des indicateurs négatifs. Le taux d'homicide au Québec, deux par ıo.ooo de population, est le quart de celui des Etats-Unis où huit personnes par Io.000 sont assassinées chaque année. Quant au suicide, le taux québécois, qui a doublé au cours de la période de grand changement social qu'on dénomme la Révolution tranquille, est encore - exception faite des jeunes hommes de I5 à ig ans - plus bas que ceux de la plupart des sociétés industrialisées.

Lorsqu'on se réfère à des indicateurs plus qualitatifs, comme ceux touchant la paix sociale et le racisme, on découve au Québec une socièté d'une civilité vraiment exceptionnelle. Il n'y a pas eu une seule émeute impliquant des morts multiples (plus d'une personnel au Québec depuis la première grande guerre; et il n'y a pas eu dans toute l'histoire du Québec une seule instance documentée de violence anti-sémite qui ait conduit à des blessures corporelles! Que ceux qui se complaisent à mettre en question la qualité de la démocratie québécoise regardent chez eux pour voir s'ils peuvent en dire autant. 
Une telle qualité de vie et une telle démocratie ne sont pas des phenomènes gratuits. Pour arriver à un tel résultat, il a fallu un ensemble de conventions et de moeurs au sein de la société civile, et une culture politique - un capital social comme dirait Raymond Breton - porteuse des meilleurs acquis de la civilisation occidentale. Et ici on touche à une caractéristique de la société québécoise qui est peu comprise par ceux qui dédaignent la qualité de la démocratie québécoise, ceux qui voudraient introduire les Québécois aux fondements de la société démocratique et moderne: le Québec a déjà, de par son patrimoine culturel français, britannique et chrétien avec lequel il n'a pas rompu, tous ces fondements. On imagine nous apporter la modernité et le libéralisme en considérant le « libéralisme contractuel » de John Rawls comme le standard international de ce qu'est la démocratie moderne. Cependant, dans la mesure où nous sommes héritiers culturels, en ligne directe, de deux des grandes traditions culturelles de l'Europe d'où est née la démocratie moderne, nous avons nous-mêmes découvert ces principes; et nous trouvons la manifestation néo-libérale - le libéralisme bourgeois que le contractualisme de Rawls glorifie - en souffrance sur le plan de la civilisation. Quand on voit une société où des gens meurent faute de soins médicaux adéquats et où des citoyens sont abattus sauvagement en pleine voie publique, cela nous inspire des doutes quant à savoir si cette société nord-américaine anglo-saxonne est elle-même une sociēté démocratique et libérale.

\section{LA CONSTITUTION QUÉBÉCOISE}

En somme, le corpus de conventions et de moeurs de la société civile québécoise, aussi bien que la culture politique québécoise, sont des réalités à prendre en considération: ensemble ils constituent ce que nous appelons dans nos traditions intellectuelles (par exemple, Edmund Burke et Alexis de Tocqueville) la constitution de la société là distinguer de l'emploi qu'on fait du mot en américain contemporain). Cette constitution, essayons d'en dégager les axes principaux.

De ces axes, nous en dénombrons six, dont chacun est la conséquence de plusieurs facteurs allant des vicissitudes de l'histoire, des conditions de peuplement, de la petite échelle de la société jusqu'à la géographie. Nous ne tenterons pas d'expliquer les origines de ces six dimensions de la constitution québécoise. Ici il s'agit tout simplement de les identifier et d'en être conscients. 
Historiquement, tous les observateurs occidentaux qui ont séjourné au Québec ont èté impressionnés par l'existence d'un très haut degré de civililé dans la société québécoise. Cette civilité se manifeste par le peu de violence, verbale et physique, qu'on observe dans les échanges publics au Québec. Il existe aussi dans les moeurs de la sociéte civile québécoise un fond d'égalitarisme qui fait en sorte qu'il puisse y avoir une familiarité entre tous en public, et qui incite à la justice sociale. Et, bien qu'ils soient conformistes (conséquence d'un type de sociabilité particulière), les Quẻbécois sont épris d'un individualisme qui a comme support matériel un régime de propriété privée qui leur est très cher ... un matérialisme individualisant.

Civilité, égalitarisme et engouement pour la propriété privée, voilà autant de façons de concevoir et de gérer la société civile. Quatrièmement, pour ce qui est de notre propos, les Québécois partagent un sentiment d'identification collective qui anime une véritable conscience nationale. En cinquième lieu, il y a dans cette socièté une culture politique d'inspiration britannique où l'on privilégie la souveraineté parlementaire, la constitution non écrite et l'autonomie locale. Appelons cette culture politique particulière, le parlementarisme. Et en sixième lieu, il y a dans la société québécoise une élite culturelle, un milieu cultivé où on partage et valorise un univers de connaissances culturelles.

Fort de cette " constitution », le Québec a su se protéger et se perpétuer. Cest sûr, le Québec contemporain a connu des courants idéologiques et des réaménagements sociaux qui ont mis en péril un ou plusieurs de ces piliers de sa Constitution. Il y a eu un temps où un certain corporatisme a eu trop d'ampleur; plus récemment encore, nous nous sommes laissès séduire par le mirage des institutions politiques républicaines; et tout dernièrement, nous sommes passés près de liquider l'élite culturelle en se fiant trop à une technocratie doublée d'une élite d'affaires. De fait, le plus grand danger qui guette la constitution québécoise, c'est précisément une technocratie de tendance républicaine qui veut se supplanter à la société civile. Ce qui n'a pas aidé, c'est que le Québec a connu depuis les années soixante une sur-centralisation de l'administration publique et un engouement pour les « Droits de la personne »: tous deux l'œuvre des technocrates qui sont les premiers à benéficier de la dévalorisation et de l'affaiblissement des moeurs et de l'éthique de la société civile. Toutefois, en ce qui concerne sa culture politique, le Québec contemporain est demeuré constant: les institutions 
politiques parlementaires, la souveraineté parlementaire et la constitution non écrite (celle d'avant $\mathbf{1 9 8 2}$ ) demeurent.

En effet, au Québec, nous valorisons les institutions parlementaires. Cette année nous célébrons le bicentenaire de l'Assemblée nationale (1792) après sa création en vertu de l'Acte constitutionnel de décembre 179I. L'Ontario, dont le parlement date du même acte, a laissé passer ce bicentenaire sans aucune célébration publique. De plus, le Québec a développé des mécanismes d'accès au parlement, tel son système de commissions parlementaires permanentes et itinérantes; instance où des individus, ou des groupes pervent faire valoir leur point de vue lors d'une consultation parlementaire. Et de fait, l'institution elle-même du parlement québécois a encore beaucoup de légitimité auprès des Québécois. Lors des sessions de la Commission parlementaire Bélanger-Campeau une proportion considérable de la population suivait les audiences à la télévision! Le succès avec lequel le Parti québécois s'est servi des institutions parlementaires pour promouvoir le français a contribué à cette légitimation auprès de la population.

Comme le Québec n'a pas adhéré à la nouvelle constitution canadienne de 1982 qui a subordonné les parlements canadiens à l'interprétation des cours de justice, le Québec n'a pas encore explicitement endossé la rupture de 1982 . L'action du parlement canadien, et de ceux des neuf autres provinces qui ont entériné les mesures de 1982, était et demeure anticonstitutionnelle. $\mathrm{Et}$ ceci est dù au fait que dans notre culture politique la seule chose qu'un parlement ne peut pas faire, c'est d'aliéner ses propres pouvoirs; et les parlementaires fédéraux et ceux des neuf autres provinces canadiennes ont fait cela en mettant en place le Canada Act avec sa Charte enchâssée.

La Chambre des Communes ne peut renoncer à la portion d'autoritè qui lui appartient. l'engagement ou pacte social - ce qu'on appelle gèneralement la Constitution - interdit de telles violations ou de tels abandons'.

De plus, dans son fonctionnement intérieur le gouvernement du Québec reconsidère la pertinence des politiques des années soixante et soixante-dix; par exemple, en démembrant les commissions scolaires régionales pour ainsi remettre aux commissions scolaires locales les écoles secondaires; en procédant à une remise aux municipalités des responsabilités qu'on leur avait enlevées au cours de la Révolution

I. Edmund Burke, Réflexion surla lévolution de France, Hachette, 1989, p. 26. 
tranquille; en faisant l'autocritique d'un révisionnisme qui avait défini tout ce qui s'est passé avant ig6o (et après 1850) comme la grande noirceur; et, plus important encore, en redécouvrant l'importance de la société civile et de la famille. Constatant les possibilités de l'ancienne constitution - la loi Ior par exemple - et ayant vécu ce que l'abandon de la culture politique parlementaire en faveur d'une vision néo-libérale peut amener - la révolution « canadienne » de I 982 qui, parmi d’autres choses, a délégitimé la loi Ior - nous commençons à mettre de côté certains rêves républicains.

\section{LE COUP DE FORCE DE 1982}

Effectivement, Ig82 est bel et bien un exemple de ce qui peut se produire lorsque nous essayons, dans le contexte géo-politique qui est le nôtre, de choisir une constitution. Les révolutionnaires de 1982 ont créé une situation où le gouvernement, même le pays en tant qu'entité politique, ne peut plus agir sur sa constitution; et où, même à l'intérieur de la constitution, le parlement est souvent empêché d'agir dans l'intérêt public.

La première affirmation - le pays ne peut plus agir sur sa constitution - se reflète dans l'imbroglio constitutionnel actuel. Avec les règles d'amendement que le parlement ne contrôle plus, nous nous dirigeons vers une impasse totale. Pour ce qui est de la deuxième affirmation, la capacité rèduite du parlement d'agir selon les circonstances dans l'intérêt public, le meilleur exemple est la mise en échec par la cour suprême de la loi qui devait mettre fin à la publicité sur le tabac.

Et pire encore, malgré la réalité inéluctable du fait que si nous voulons un Etat politique distinct des Etats-Unis, nous avons déclenché en Ig82 un processus d'américanisation de notre culture politique. Il n'y aurait plus, à la longue, de moyen de savoir qui est canadien; et justement, depuis peu, un citoyen américain pourrait devenir Premier ministre du Canada. C'est l'effet combiné de la double citoyenneté (1977) et des dispositions du Traité de libre échange (1988) qui a donné ce résultat imprévu, résultat que le Commissaire de la citoyenneté confirme.

\section{La SÉPARATION dU Canada}

Quoi faire face à cela, cest-à-dire face à cette révolution qui risque d'entraîner la déperdition de la constitution actuelle du Québec? Le Québec doit agir pour protéger sa constitution, et pour ce faire, s'opposer à ce que la révolution canadienne de 1982 ne se réalise en terre québécoise. 
Mais comment agir ainsi lorsque le Québec fait encore partie de la fédération canadienne? Il faudrait que le parlement du Québec somme le reste du Canada de se désister de son anticonstitutionnalisme, de reconnaître que ig82 était une erreur de parcours (comme l'Union de 1840 l et de revenir à la constitution canadienne d'avant Ig82. Il faudrait aussi faire savoir au Canada anglais que s'il persiste dans son comportement déloyal, il serait mieux qu'il se sépare du « Canada qui reste », c'est-à-dire du Québec. I’ serait à la charge du Canada-anglais de faire des démarches pour réaliser sa sécession et pour mettre en place un Etat successeur qui pourrait s'appeler la République du Canada ou la ROC!

Département de sociologie et d'anthropologie Université de Concordia 